OPEN ACCESS

Edited by:

Pedro A. Reche,

Complutense University of Madrid,

Spain

Reviewed by:

Cristina Maccalli,

Sidra Medicine, Qatar

Gary Kohanbash,

University of Pittsburgh, United States

*Correspondence:

Peter D. Sun

psun@nih.gov

Specialty section:

This article was submitted to Vaccines and Molecular Therapeutics, a section of the journal

Frontiers in Immunology

Received: 10 December 2021

Accepted: 21 January 2022

Published: 10 February 2022

Citation:

Sim MJW and Sun PD (2022)

$T$ Cell Recognition of Tumor

Neoantigens and Insights Into

T Cell Immunotherapy.

Front. Immunol. 13:833017.

doi: 10.3389/fimmu.2022.833017

\section{T Cell Recognition of Tumor Neoantigens and Insights Into T Cell Immunotherapy}

\author{
Malcolm J. W. Sim and Peter D. Sun* \\ Laboratory of Immunogenetics, National Institute of Allergy and Infectious Diseases, National Institutes of Health (NIH), \\ Rockville, MD, United States
}

In cancer, non-synonymous DNA base changes alter protein sequence and produce neoantigens that are detected by the immune system. For immune detection, neoantigens must first be presented on class I or II human leukocyte antigens (HLA) followed by recognition by peptide-specific receptors, exemplified by the T-cell receptor (TCR). Detection of neoantigens represents a unique challenge to the immune system due to their high similarity with endogenous 'self' proteins. Here, we review insights into how TCRs detect neoantigens from structural studies and delineate two broad mechanistic categories: 1) recognition of mutated 'self' peptides and 2) recognition of novel 'non-self' peptides generated through anchor residue modifications. While mutated 'self' peptides differ only by a single amino acid from an existing 'self' epitope, mutations that form anchor residues generate an entirely new epitope, hitherto unknown to the immune system. We review recent structural studies that highlight these structurally distinct mechanisms and discuss how they may lead to differential anti-tumor immune responses. We discuss how $T$ cells specific for neoantigens derived from anchor mutations can be of high affinity and provide insights to their use in adoptive T cell transfer-based immunotherapy.

Keywords: T cell receptor, tumor neoantigen, binding affinity, TCR and neoantigen bound HLA complex, group I and II neoantigens, adopt T-cell transfer immunotherapy, tumor infiltrating lymphocytes

\section{INTRODUCTION}

Immunotherapy is revolutionizing the treatment of cancer and understanding how the immune system detects tumors will lead to improved and novel therapies $(1,2)$. Tumor transformation is associated with a multitude of cellular and genetic changes including somatic mutations that alter protein sequence (3-5). Unleashing $\mathrm{T}$ cells specific for these mutations is thought to be one mechanism for the therapeutic effect of checkpoint blockade immunotherapy (CBI) $(6,7)$, and maybe the 'common pathway' for many effective immunotherapies (8). Extensive tumor genome and exome sequencing studies have revealed the landscape of tumor mutations to be broad, however only a fraction of these appear immunogenic $(9,10)$. Generating tools that can identify immunogenic neoantigens from sequence will greatly facilitate the deployment of neoantigen based vaccines and other immunotherapies (11). However, the features that distinguish immunogenic and non-immunogenic mutations are poorly defined. Structural biology has been invaluable to understanding the immune system (12-14). By studying TCRs with demonstrated clinical efficacy, structure-based approaches can provide insight into biochemical and structural 
features associated with therapeutic success (15). Here, we review recent structural studies of how TCRs detect immunogenic neoantigens and discuss how some biochemical properties, such as antigenic binding affinity, may influence clinical outcome of adoptive $\mathrm{T}$ cell therapy.

\section{BASICS OF T CELL RECOGNITION AND ANTIGEN PRESENTATION}

\section{Antigen Presentation}

$\mathrm{T}$ cell recognition is a multi-step process that includes two steps where structural biology can provide unrivaled insight. The first is antigen presentation, where peptide antigens are presented on the cell surface on class I or class II human leukocyte antigens (HLA) (16). HLA-I is expressed on all nucleated cells, including tumors and is the ligand for TCRs expressed on $\mathrm{CD}^{+}$cytotoxic T cells. Humans carry three classical HLA-I genes, encoded by HLA-A, HLA-B and $H L A-C$ that encode the HLA-I heavy chain, which forms the HLA-I molecule in complex with bound peptide and the invariant chain beta-2-microglobulin $\left(\beta_{2} \mathrm{M}\right)$ (Figure 1A). HLA-I bound peptides are typically 8-11 amino acids long, due to a closed peptide binding groove that prevents longer peptides from extending at either termini. At homeostasis, HLA-I binds 'self peptides, which are derived from the proteasomal degradation of old proteins (retirees) or the products of stalled ribosomal translation known as defective
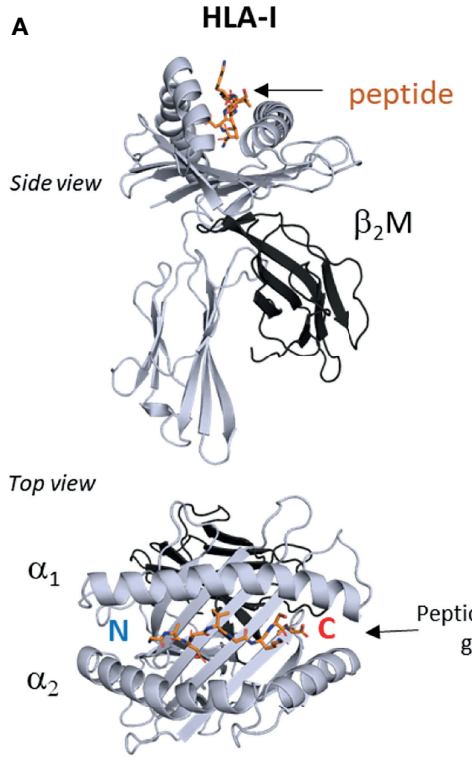

c

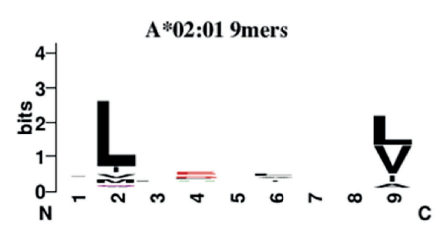

HLA-C*08:02 9mers

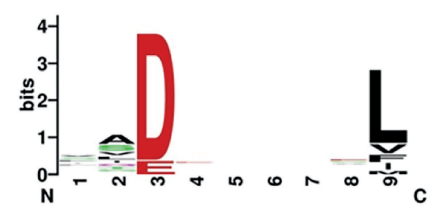

B

HLA-II
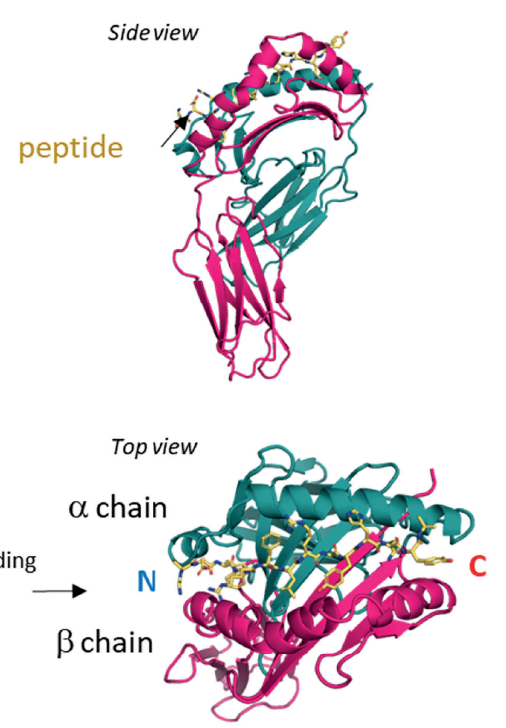

FIGURE 1 | HLA-I, HLA-II and TCRs. (A) Structure of HLA I molecule. Contains HLA-I heavy chain, $b_{2} M$ and bound peptide. Peptide binding groove consists of $a_{1}$ and $\mathrm{a}_{2}$ domains of HLA-I heavy chain (PDB entry 6ULI). (B) Structure of HLA-II molecule. Contains HLA-II alpha and beta chains and bound peptide. Peptide binding groove is shared by alpha and beta domains (PDB entry 1AQD). (C) Examples of peptide motifs for 9mer peptides eluted from two different HLA-I molecules, HLA$A^{\star}$ 02:01 and HLA-C*08:02. Single letter amnio acid code is used. Size of letter indicates prominence of that residue. Anchor residues are defined by restricted amino acid usage, commonly at p2, p3 and p9. (D) Structure of ab TCR showing constant (C) and variable (V) regions and six CDR loops (PDB entry 6ULN). 
ribosomal products (DRiPs) $(17,18)$. These peptides are then funneled into the ER by the transporter associated with antigen presentation (TAP) $(16,18)$, where they are loaded onto HLA-I molecules in a competitive manner facilitated by chaperone proteins such as TAPASIN (19). In infections or cancer, pathogen derived sequences or neoantigens enter the HLA-I presentation pathway the same way as 'self peptides in the form of 'retirees' and DRiPs $(17,18,20)$.

The ligand for TCRs expressed by $\mathrm{CD}^{+}$helper $\mathrm{T}$ cells is HLA-II, which is expressed on professional antigen presenting cells (APC) such as dendritic cells, monocyte/macrophages and B cells. HLA-II consists of bound peptide and two chains alpha and beta encoded by different polymorphic genes (Figure 1B). HLA-II bound peptides are typically 15 amino acids in length, longer than HLA-I due to its open-ended peptide binding groove (PBG). There is some evidence that tumors can directly express HLA-II (21) but generally, recognition of HLA-II restricted neoantigens is thought to be through interactions with APCs (22). HLA-II binds peptides in a late endosomal compartment where it intercepts endocytosed proteins, which are degraded by endosomal proteases (16). Chaperones such as HLA-DM facilitate exchange for high affinity peptides (23). Neoantigens can enter this pathway via endocytosis of apoptotic or necrotic tumor cells bearing specific mutations.

The genes encoding classical HLA molecules are the most polymorphic across human populations, with over 10,000 HLA-A, -B, -C and 5,000 HLA-II protein variants $(24,25)$. The majority of this polymorphism is located within the PBG, a specialist structural fold that allows HLA proteins to bind peptides of correct sequence via non-covalent interactions. As peptide binding to HLA is highly competitive, only peptides that best satisfy the biochemical requirements of the particular PBG will escape quality control and be presented on the cell surface (19). The PBG is made of pockets (A-F) that exhibit localized preferences for specific biochemical characteristics, such as charge, size, hydrophobicity, polarity and combinations of all (26). The A-F pockets run from the peptide $\mathrm{N}$ to $\mathrm{C}$ termini, with the $\mathrm{A}$ and $\mathrm{F}$ pockets coordinating the conserved amide and carboxylic acid groups. For HLA-I binding, there are critical residues at $\mathrm{p} 2$ or $\mathrm{p} 3$ and the $\mathrm{C}$-terminus $(\mathrm{p} \Omega)$ positions, known as anchor residues. Amino acid substitutions at anchor residues substantially alter peptide binding and HLA stability. The fraction of the proteome bound by HLA molecules is known as the immunopeptidome (27), and these peptides can be eluted, and sequenced by mass spectrometry (28-31). Immunopeptidomes are highly diverse consisting of hundreds to thousands of different 'self peptides for each HLA allotype. Allotype-specific peptide motifs are derived from immunopeptidomes of different HLA-I and HLA-II molecules and demonstrate peptide sequence restriction at anchor residues and variation at non-anchor residues (Figure 1C). Crystal structures of HLA-I and HLA-II molecules with specific peptides confirm these motifs by revealing the number of interactions between the PBG and peptide anchor side chains. It is possible to classify tumor mutations into three categories; (1) mutation occurs at a non-anchor residue of an existing 'self peptide, (2) mutation occurs at anchor residue impacting antigen presentation, (3) mutation falls in a peptide sequence not presented by host HLA allotype. Herein we use nomenclature defined by Fritsch et al. (32); group 1 neoantigens exhibit similar HLA binding affinities between mutant and 'wild type' (WT) peptides and the mutation lies in a non-anchor residue in an existing 'self' peptide. Group 2 neoantigens exhibit significantly increased HLA binding affinity compared to WT peptides due to mutations that form novel anchor residues.

\section{T Cell Recognition}

Once presented by HLA-I and HLA-II molecules, neoantigen peptides can be detected by $\mathrm{T}$ cells via the alpha-beta $\mathrm{T}$ cell receptor ( $\alpha \beta$ TCR). TCR $\alpha$ and $\beta$ chains consist of constant $(\mathrm{C})$ and variable $(\mathrm{V})$ regions, where the membrane distal $\mathrm{V}$ regions engage peptide-bound HLA complexes (Figure 1D). From structural studies of TCR : HLA complexes, general rules have emerged $(33,34)$. The $\mathrm{V}$ regions contact peptide and HLA via three complementarity determining regions (CDR1-3) that form six flexible loops, generated through VDJ recombination $(33,34)$. Germline encoded CDR1 and CDR2 engage the HLA protein, while CDR3s interact with bound peptide. The TCR V $\alpha$ is centered over the $\alpha 2$ helix of HLA-I (the $\beta$ chain of HLA-II) while the TCR V $\beta$ chain is centered over the $\alpha 1$ helix of HLA-I (the $\alpha$ chain of HLA-II). The TCR docks diagonally, with the V $\alpha$ angled towards the peptide $\mathrm{N}$-terminus and the $\mathrm{V} \beta$ angled towards the peptide C-terminus. Substitutions that disrupt key CDR interactions with peptide or HLA are sufficient to reduce or eliminate binding and prevent $\mathrm{T}$ cell activation (33-35). During $\mathrm{T}$ cell development in the thymus, $\mathrm{V} \alpha$ and $\mathrm{V} \beta$ chains are generated by recombining single $\mathrm{V}(\mathrm{D}) \mathrm{J}$ gene segments from a large repertoire of V, D and J segments (only V and J for $\alpha$ chain) $(36,37)$. Single gene segments recombine to form each chain allowing for considerable $\mathrm{V} \alpha$ and $\mathrm{V} \beta$ diversity, which when combined to form $\alpha \beta$ pairs have a theoretical upper limit of over $10^{15}$ unique TCRs. $\mathrm{V}$ gene segments encode CDR1 and CDR2 sequences, while CDR3 is located at the $\mathrm{V}(\mathrm{D}) \mathrm{J}$ boundary and due to base editing is the most variable region. During T cell development the pre-selection TCR repertoire is pruned to eliminate TCRs with the potential for autoreactivity, while also selecting for useful TCRs with the ability to detect 'self HLA. Before leaving the thymus, each TCR is selected for moderate affinity for 'self peptide-bound HLA complexes (positive selection), while TCRs with too high affinity for 'self peptide-bound HLA are deleted (negative selection) $(37,38)$. Consequently, many TCRs that recognize group 1 neoantigens may be eliminated due to their high similarity with WT 'self peptides.

\section{TWO WAYS TO DETECT NEOANTIGENS}

Insights from structural and functional studies have revealed that neoantigens can be recognized in two fundamentally different ways. Group 1 neoantigens are those where the mutation occurs in a non-anchor residue of an existing 'self peptide (Figure 2). Group 2 neoantigens are where the mutation creates an anchor residue converting a previously non-HLA binding sequence into a novel non-self epitope (Figure 3). From the examples below, 

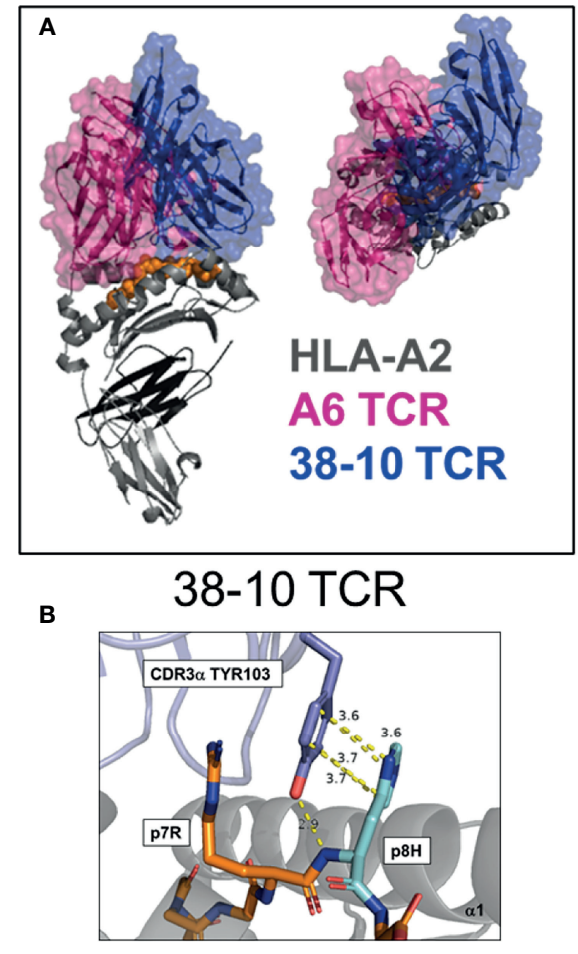

E

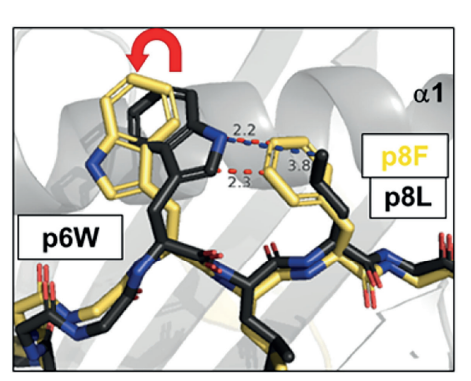

c

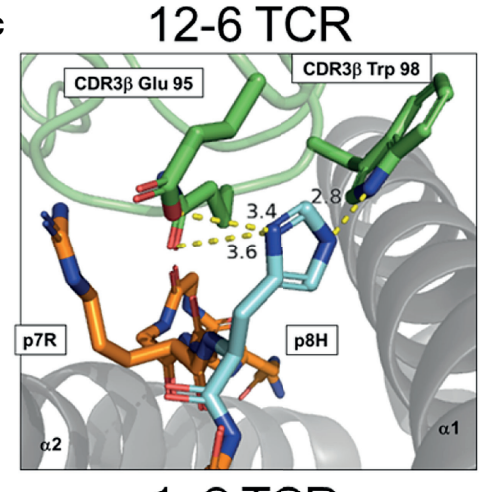

D

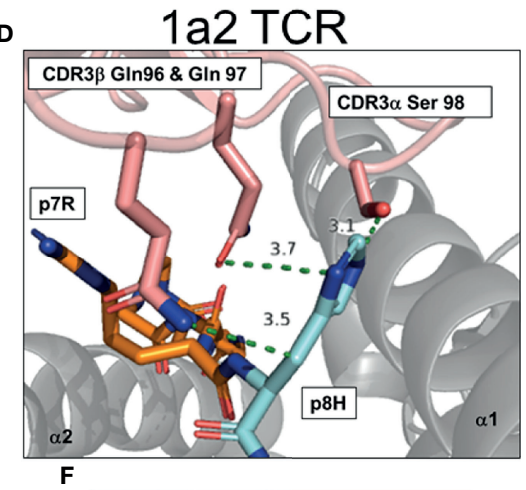

$\mathbf{F}$

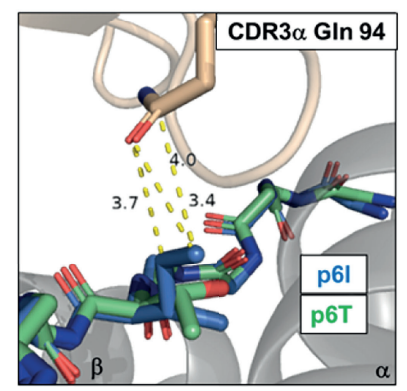

FIGURE 2 | Multiple strategies to detect mutated 'self' epitopes, group 1 neoantigens. (A) Docking of A6 TCR and 38 -10 TCR on HLA-A2 displaying C-terminal shift of 38-10 TCR specific for p53 R175H (PDB entry 1AO7, 6VRN). (B-D) Dominant TCR contacts with p8 of HMTEWRHC, p53 R175H neoantigen presented by HLA-A2 by 38-10 TCR (6VRN) (B), 12-6 TCR (6VRM) (C) and 1a2 TCR (6QVO) (D). (E) Peptide pre-organization confers structural dissimilarity. Peptide p8 in HHAT L75F neoantigen KQWLWWLL pre-organizes p6W into optimal TCR binding confirmation to allow effective tumor detection (6UK2,6UK4). (F) Direct recognition of exposed mutation. Mutant p6I in GELIGILNAAKVPAD TPI neoantigen confers more TCR-E8 contacts that WT p6T (2IAM, 2IAN).

we review how there are multiple ways for TCRs to solve the problem of identifying single amino acid substitutions in preexisting 'self peptides (group 1) (39-41). Next we review our own work on the presentation and $\mathrm{T}$ cell recognition of two group 2 neoantigens derived from the same G12D mutation in the oncogene KRAS (15). To define neoantigens as group 1 or group 2, researchers often utilize prediction algorithms such as NetMHCPan to predict the HLA binding affinities of WT and mutant peptides (42). For group 1 neoantigens the predicted binding affinities will be similar, while for group 2 neoantigens the mutant peptide has considerably higher binding affinity than the WT sequence. For detailed studies of specific neoantigens, it is important to validate whether neoantigens fall into group 1 or 2 using in vitro assays such as peptide loading on TAP-deficient cells or in vitro refolding assays with recombinant proteins (15, 43). Table 1 lists the HLA restrictions, neoantigen sequences and TCR affinities for the TCRs we reviewed. A summary of differences between TCR recognition of group 1 and group 2 neoantigens is shown in Figure 4.

\section{GROUP 1 NEOANTIGENS: MUTATED 'SELF' EPITOPES}

\section{Recognition of a Shared Mutated p53- R175H Neoantigen by C-Terminal Shift}

TP53 is the most mutated gene across all cancers, highlighting its critical role as a tumor suppressor (45). A significant number of 


\section{A}

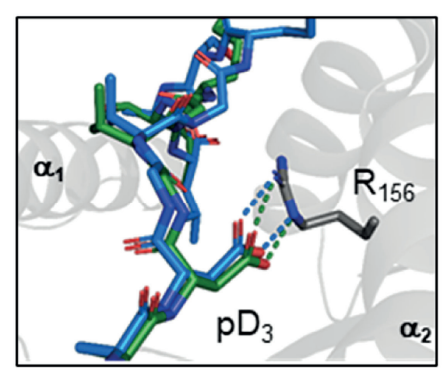

G12D9mer G12D10mer
B

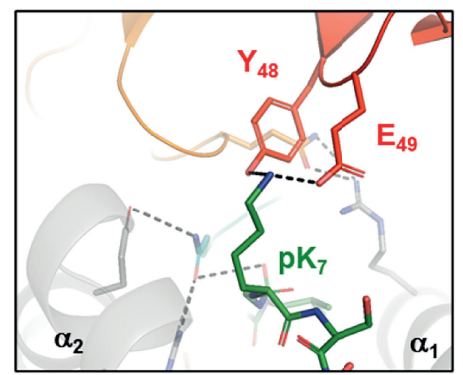

HLA-C*08:02

c TCR9d: CDR3 $\alpha$ CDR3 $\beta$

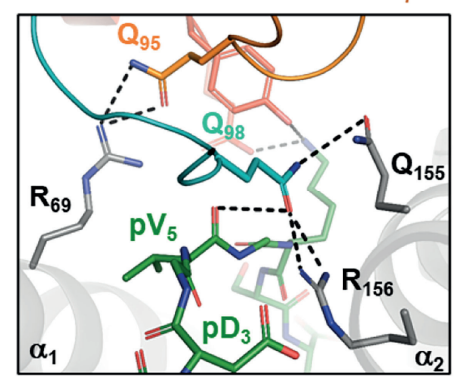

E

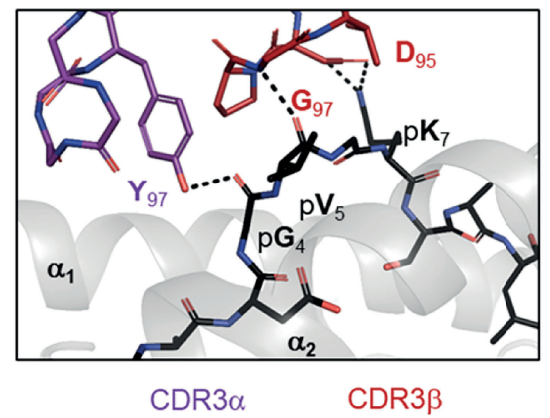

D CDR3 $\beta$ :TCR9a TCR9d
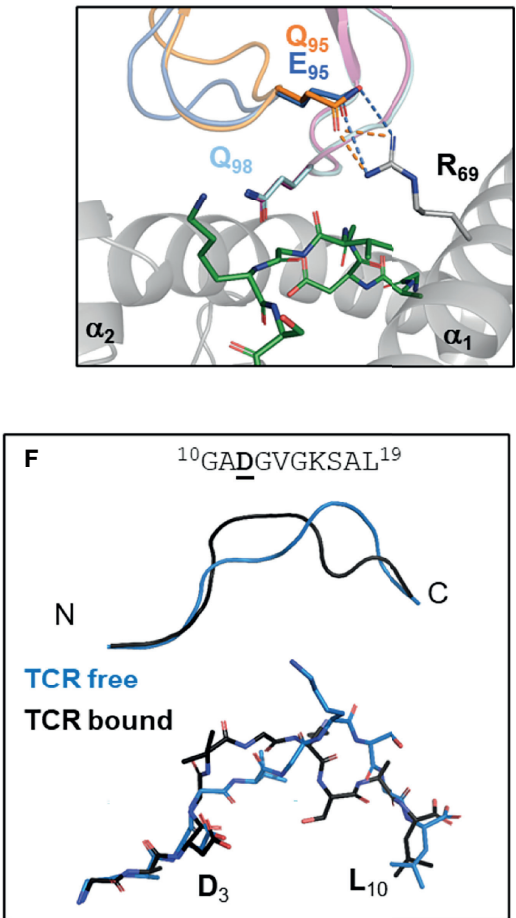

FIGURE 3 | TCR recognition of group 2 neoantigens, novel 'non-self' epitopes generated by the KRAS-G12D mutation. (A) KRAS-G12D neoantigens G12D-9mer (GADGVGKSA) and G12D-10mer (GADGVGKSAL) form a salt bridge mutant p3 Asp and HLA-C Arg 156 on $\alpha 2$ helix of HLA-C*08:02 (PDB entry 6ULI, 6ULK). (B-D) TCR recognition of G12D-9mer by TCR9a and TCR9d. (B) Shared CDR2 $\beta$ contacts with p7 Lys (6ULN). (C) Shared CDR3 $\alpha$ contacts with p5 Val and Gln 155, Arg 156 of HLA-C*08:02 (6ULN). (D) Position 95 CDR3b contact with Arg 69 of HLA-C*08:02 modifies TCR9 binding strength (6ULN,6ULR). (E, F) TCR10 recognition of G12D10mer. (E) TCR10 CDR3 $\alpha$ and CDR3 $\beta$ contacts with G12D-10mer (6UON). (F) G12D-10mer conformation in TCR free and TCR10 bound forms (6ULK,6UON).

TP53 mutations occur in the same 'hotspot' locations. Studies by the Rosenberg group at the National Cancer Institute (NCI) and others, have identified TCRs specific for the p53-R175H mutation, restricted by the common HLA-I allotype, HLA$\mathrm{A}^{\star}$ 02:01 (HLA-A2) (46-49). Approximately 5\% of p53 mutations are $\mathrm{R} 175 \mathrm{H}$, and the high frequency of HLA-A2 across populations makes this 'shared' neoantigen an attractive therapeutic target (50). In a recent study by $\mathrm{Wu}$ et al, three p53$\mathrm{R} 175 \mathrm{H}$ specific TCRs were studied, $12-6,38-10$ and $1 \mathrm{a} 2$ (39). These TCRs displayed no binding to WT $\mathrm{p} 53$ peptide but a range of affinities $\left(K_{D}, 1-40 \mu \mathrm{M}\right)$ for the $\mathrm{p} 53-\mathrm{R} 175 \mathrm{H}$ peptide
(HMTEVVRHC). As this mutation occurred at a non-HLA-A2 anchor position, the authors were able to solve structures of HLA-A2 with both WT and R175H p53 peptides. The peptide conformations in these HLA-A2 alone structures were identical, apart from the peptide position 8 (p8) side chain. The TCRs shared no $\mathrm{V} \alpha$ or $\mathrm{V} \beta$ genes and their CDR3 sequences had no obvious sequence homology, suggesting each TCR recognized the p53-R175H mutation in a different way. By solving $\mathrm{x}$-ray crystal structures of all three TCR-A2-p53-175H complexes, Wu et al. were able to answer this question directly. These TCRs displayed a canonical diagonal docking orientation but were 
TABLE 1 | Neoantigen specific TCRs with crystal structures.

\begin{tabular}{|c|c|c|c|c|c|c|c|}
\hline TCR & HLA & \multicolumn{2}{|c|}{ Peptide sequence } & Protein & Mutation position & \multicolumn{2}{|c|}{ TCR affinity (KD) } \\
\hline $12-6$ & $A^{*} 02: 01$ & HMTEWRRC & HMTEVRH & p53 & 175 & UD & $1.1 \mu \mathrm{M}$ \\
\hline $1 \mathrm{~A} 2$ & $A^{*} 02: 01$ & HMTEWRRC & HMTEVR $\underline{H C}$ & p53 & 175 & UD & $16.2 \mu \mathrm{M}$ \\
\hline 302TIL & $A^{*} 02: 06$ & KQWLVWLLL & KQWLWWLFL & Hedgehog acyltransferase & 75 & $200 \mu \mathrm{M}$ & $9 \mu \mathrm{M}$ \\
\hline E8 & DR1 & GELIGTLNĀAKVPAD & GELIGILNAAKKVPAD & Triosephosphate isomerase & 28 & ND & ND \\
\hline TCR9b & $C^{*} 08: 02$ & GAGGGVGKSA & GAD $\underline{\text { GVGKSA }}$ & KRAS & 12 & NA & $835 \mathrm{nM}$ \\
\hline TCR9C & $C^{*} 08: 02$ & GA $\bar{G} G V G K S A$ & GAD $\underline{\mathbf{D}} G$ VGKSA & KRAS & 12 & NA & $90 \mathrm{nM}$ \\
\hline TCR9d & $C^{*} 08: 02$ & GAĒGVGKSA & GAD̄ & KRAS & 12 & NA & $125 \mathrm{nM}$ \\
\hline TCR10 & $C^{*} 08: 02$ & GAG $\bar{G} G V G K S A L$ & 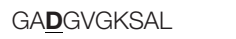 & KRAS & 12 & NA & $6 \mu \mathrm{M}$ \\
\hline
\end{tabular}

WT, wild type; MUT, mutant; UD, Undetectable; ND, Not determined; NA, Not applicable.

"*' is part of nomenclature for HLA alleles. Bold \& underline indicate site of mutation.

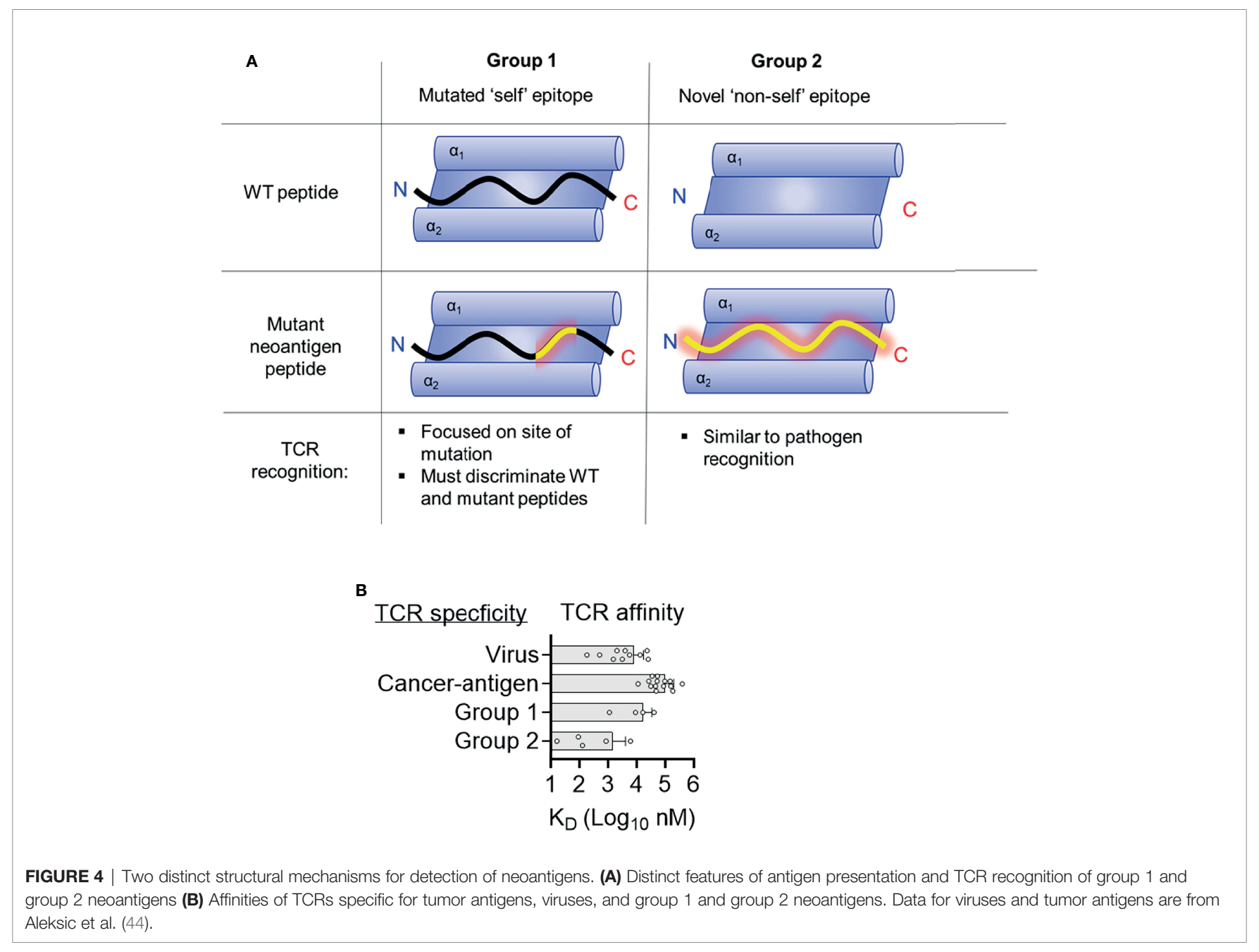

unusually shifted to peptide C-terminus, proximal to the mutation site (Figure 2A). Indeed, TCR 38-10 was the most C-terminal shifted TCR in the PDB database with a canonical orientation, with TCR 12-6 and 1a2 also high on the list (39). By shifting towards the C-terminus, these TCRs were able discriminate between WT and mutant p53 peptides as most TCR-peptide contacts with p7-Arg and p8-His, while most TCRs target the central residues p4-p6 (33). Each TCR had different footprints, but 12-6 and 1a2 were more similar and utilize their $\operatorname{CDR} 3 \beta$ to coordinate the $\mathrm{R} 175 \mathrm{H}$ mutation, while $38-10$ was 
dominated by its CDR3 $\alpha$. For TCR 38-10, CDR3 $\alpha$ Tyr103 slides between $\mathrm{p} 7 \mathrm{R}$ and $\mathrm{p} 8 \mathrm{H}$ to contact the peptide backbone, while forming $\pi-\pi$ stacking interactions with the imidazole ring of $\mathrm{p} 8 \mathrm{H}$ and van-der Waals contacts with p7R (Figure 2B). For TCR 12-6, the $\mathrm{p} 8 \mathrm{H}$ side chain is contacted by CDR3 $\beta$ Glu95 and Trp98, while CDR3 $\beta$ Gln99 contacts the peptide backbone (Figure 2C). For TCR 1a2, p7R is coordinated by CDR3 $\beta$ Asp100 and CDR1a Tyr32, while $\mathrm{p} 8 \mathrm{H}$ is contacted by CDR3 $\beta$ Gln96 and Gln97 with further contacts from CDR $3 \alpha$ Ser98 (Figure 2D). Further contacts with the HLA-A2 heavy chain and modest conformational changes were observed to fully accommodate TCR binding (39). This study highlights how three different TCRs utilize different contacts but the same broad strategy of C-terminal shift to coordinate the same mutation.

\section{Structural Dissimilarity via Peptide Pre-Organization}

In another recent study, a completely different structural solution to neoantigen recognition was observed (40). This study focused on an HLA-A ${ }^{\star} 02: 06$ restricted TCR (302-TIL) specific for a L75F mutation in hedgehog acyltransferase (HHAT) identified from a patient with ovarian cancer (40). Similar to p53-R175H, the mutation was located at $\mathrm{p} 8$ of a 9mer antigen with the sequence KQWLVWLFL. However, unlike recognition of R175H, TCR recognition was not dependent on a C-terminal shift. In fact, the relatively conservative $\mathrm{pL} 8 \mathrm{~F}$ mutation, forces $\mathrm{p} 6 \mathrm{~W}$ into an optimal TCR binding conformation due to proximity with the larger $\mathrm{p} 8 \mathrm{~F}$ (Figure 2E). Crystal structures of 302-TIL TCR in complex with both WT and mutant peptide, revealed that the p6W adopted the same conformation in both complexes. However, 302-TIL TCR had a much higher affinity for mutant peptide at $9 \mu \mathrm{M}$ compared to $200 \mu \mathrm{M}$ with WT peptide and had an especially slower off rate with mutant peptide. The best interpretation of these data are that adopting the optimal p6W conformation is slow in the context of WT peptide, but p8F 'pre-organizes' p6W into an optimal TCR binding state, allowing rapid $\mathrm{T}$ cell activation and discrimination of tumors from healthy cells.

\section{Direct Recognition of Exposed Mutation}

To date, there is one structural study of an HLA-II restricted neoantigen specific TCR identified from a melanoma specific CD4+ TIL cell line TIL1558 (41). TCR-E8 was identified as HLADR1 restricted and specific for a Thr28Ile mutation in the enzyme triosephosphate isomerase (TPI), with the peptide GELIGILNAAKVPAD. TCR-E8 tetramers displayed binding only to mutant TPI-T28I peptide but not WT peptide by surface plasmon response (SPR), but the binding was too weak to determine a $\mathrm{K}_{\mathrm{D}}$ using TCR monomers. The pT6I substitution had no impact on peptide stability of HLA-DR1 and thus was likely recognized due to novel TCR contacts. Complex structures of TCR-E8 with HLA-DR1 bound to WT and mutant TPI peptides were solved. In the complex with WT peptide, p6Thr is buried and forms only one TCR contact. In contrast, the mutant p6Ile is exposed and protrudes from the HLA-DR1 surface forming three TCR contacts, providing a higher buried surface area and improving the shape complementarity between TCR and HLA-DR1 (Figure 2F).

\section{GROUP 2 NEOANTIGENS: NOVEL 'NON-SELF' EPITOPES GENERATED BY ANCHOR RESIDUE MUTATIONS}

The examples above involve direct comparisons between WT and mutant peptides as the mutations did not occur in anchor residues and had minimal effects on HLA stability. Group 2 neoantigens are peptides for which mutations create an anchor residue required for HLA binding and thus these epitopes acquired HLA presentation through mutation. In these cases, the WT peptides are generally not presented by HLA for exactly the opposite reason that they lack the right anchor residues for HLA binding. In theory, these epitopes appear as entirely 'nonself and completely novel to the immune system analogous to pathogen derived peptides. They form specific interactions with their cognate TCRs and generate robust T cell response $(15,51)$.

\section{KRAS-G12D Mutation Creates Two HLA-C*08:02 Restricted Neoantigens}

Oncogenic mutations in the RAS family of small GTPases (K-, $\mathrm{N}-, \mathrm{H}-\mathrm{RAS}$ ) are second only in frequency to those in TP53 (20, $52,53)$. These mutations occur in 'hotspots' at positions 12, 13 and 61 of RAS protein and lead to constitutive RAS activation promoting tumor transformation $(20,54)$. The high frequency of these mutations makes them attractive targets for immunotherapy. In 2016, a seminal study demonstrated that adoptive transfer of expanded TILs specific for Gly 12 to Asp mutation in KRAS (KRAS-G12D) lead to tumor regression in a patient with metastatic colorectal cancer (51). Adoptive transfer of expanded TILs specific for KRAS-G12D led to complete regression of all but one metastatic lesion. The remaining lesion lost $H L A-C^{\star} 08: 02$ from its genome demonstrating that clinical efficacy in this case was most likely through HLA$C^{\star}$ 08:02 presentation of KRAS-G12D neoantigens (51). Four HLA-C*08:02 restricted KRAS-G12D specific TCRs were identified from this study in addition to one more identified in a 2015 study (55). Of these five TCRs, four were KRAS-G12D 9mer specific (G12D-9mer; GADGVGKSA), while one was KRAS-G12D 10mer specific (G12D-10mer; GADGVGKSAL). The G12D-9mer specific TCRs are TCR9a, 9b, 9c \& 9d, while TCR10 is the G12D-10mer specific TCR. For both neoantigens, the mutation occurred at Gly 12 of KRAS resulting in Aspartate at peptide position three. The G12D-10mer differs from G12D9 mer by having one additional Leu at the C-terminus, the next residue in the KRAS sequence.

By solving crystal structures of HLA-C ${ }^{\star} 08: 02$ with G12D9 mer and G12D-10mer alone and in complex with cognate TCRs, we were able to directly assess the impact of G12D mutation on HLA-C binding and T cell recognition (15). Both G12D-9mer and G12D-10mer bind HLA-C*08:02 via a saltbridge formed between $\mathrm{p} 3$ Aps and Arg156 of the $\alpha_{2}$ helix of HLA-C $^{\star}$ 08:02 (Figure 3A). This salt-bridge is a critical anchor interaction required for all $\mathrm{HLA}-\mathrm{C}^{\star} 08: 02$ binding peptides as evidenced by the fact that $97.6 \%$ of peptides eluted from HLA-C $^{\star} 08: 02$ had either Asp or Glu at p3 $(28,29)$. In contrast, the WT peptide with $\mathrm{p} 3$ Gly cannot form a salt-bridge with the 
HLA-C ${ }^{\star} 08: 02$ and consequently only G12D KRAS peptides stabilized HLA-C ${ }^{\star} 08: 02$ on cells or as recombinant protein (15). Thus, the G12D mutation generates a novel anchor interaction endowing mutant but not WT KRAS peptides to bind HLA-C*08:02 and be presented for immunosurveillance.

Class I HLA binding peptides contain a C-terminal anchor, the side chain of which is orientated to toward the interior of HLA peptide binding grove (F pocket) and is buried from solvent $(26,56)$. The C-terminal residue is typically large, hydrophobic or charged and interacts with a complementary hydrophobic or charged F pocket $(26,28,56)$. The G12D-9mer contains an unusual C-terminal anchor (Ala), which does not fully occupy the F-pocket (15). Despite this, G12D-9mer bound HLA-C ${ }^{\star}$ 08:02 with canonical conformation with p9 Ala positioned into the class I hydrophobic pocket (15). The most common C-terminal residue for HLA-C $\mathrm{C}^{\star} 08: 02$ bound peptides is Leu, however Ala is present in approximately $1 \%$ of peptides (57). Consistent with Ala being sufficient but not an optimal C-terminal anchor, substitution of G12D-9mer p9 Ala to Leu improved binding to HLA-C ${ }^{\star} 08: 02$ and T cell recognition by TCR9a $(15,57)$. In the G12D-10mer, its canonical C-terminal anchor and the saltbridge with p3 Asp, forced the G12D-10mer to bulge peaking at p7 Lys, adopting an entirely different conformation than G12D-9mer (15). This resulted in two HLA-C*08:02 bound G12D neoantigens, with distinct peptide conformations even though their sequences differed by only one amino acid.

TCR recognition of KRAS-G12D peptides contained the general features observed in many of TCR : HLA complexes (33). However, the unique aspects of KRAS-G12D specific TCRs provided insights to how tumor infiltrating $\mathrm{T}$ cells recognize tumors and the potential beneficial traits for selecting therapeutically effective TCRs (15). Consistent with their distinct peptide conformations, the G12D-9mer and G12D10 mer specific TCRs used different $\mathrm{V} \alpha$ and $\mathrm{V} \beta$ genes and shared no CDR sequences $(15,51)$. The four G12D-9mer specific TCRs (TCR9a, 9b, 9c and 9d) used the same V $\alpha$ and $\mathrm{V} \beta$ genes, with almost identical $\operatorname{CDR} 3 \alpha$ sequences despite the fact that TCR9d was identified from a different individual to the other three TCRs, suggesting TCR9 is a public TCR $(51,55,58)$. The four G12D-9mer specific TCRs displayed a range of high affinities, from $16 \mathrm{nM}$ (TCR9a) to 835nM (TCR9b) (15). TCR9 docks onto peptide:HLA-C as a rigid body without significant changes in peptide nor HLA-C conformation and most peptide contacts are made through $\operatorname{CDR} 3 \alpha$ and $\operatorname{CDR} 2 \beta$ residues, conserved across TCR9a-d (Figures 3B, C). CDR3 $\beta$ is the only segment with significant sequence variation among TCR9a-d. Structures of TCR9a and TCR9d with HLA-C ${ }^{\star} 08: 02-G 12 D-$ 9 mer revealed the same contact with CDR3 $\beta$ position 95 and HLA-C Arg 69 on the $\alpha_{1}$ helix (15). The biochemical strength of the CDR3 $\beta$-HLA-C interaction correlated with TCR9 affinity, with TCR9a Glu95 forming a salt-bridge and conferring the strongest binding. TCR9c and 9d formed h-bonds with HLA-C Arg 69 via Gln 95 and had intermediate affinities, while TCR9d could not contact HLA-C Arg 69 via Arg 95 in its CDR3 $\beta$ and consistently had the lowest affinity (15) (Table 1). Recognition of the G12D-10mer by TCR10 was dependent on CDR3 $\alpha$ and
CDR3 $\beta$ interactions with the central core of peptide (Figure 3D). Interestingly, TCR10 binding induced a conformational change in G12D-10mer peptide that is different from the peptide conformation presented by HLA-C ${ }^{\star} 08: 02$ in the absence of the receptor (15).

G12D-9mer and G12D-10mer share VGK (p5-p7) exposed to TCR, however their discrete conformations resulted in distinct TCR contacts without any detectable conservation between the G12D-9mer and -10mer specific TCRs (15). For example, both TCR9 and TCR10 formed charge interactions with the peptide Lys at position 7, TCR9 used a Glu residue from CDR2 $\beta$ and TCR10 used an Asp residue from its CDR3 $\beta$, respectively, to facilitate the charge contacts (15). TCR9a-c and TCR10 were identified in the same individual and the lack of conservation in $\mathrm{V}$-gene and CDR3 sequences supports the conformational uniqueness of these neoantigens. Indeed, there is limited cross reactivity between the two classes of TCRs $(15,51)$. TCR10 is solely G12D-10mer restricted, exemplifying the conformational dependency of its interaction with G12D-10mer. TCR9a displayed weak recognition of G12D-10mer and structural modeling suggests TCR9a could interact with G12D-10mer in its TCR unbound conformation (15). However, it is also possible that G12D-10mer degrades during in vitro assays to confer weak recognition by TCR9, as we did not observe any TCR9 binding to G12D-10mer using recombinant protein (15). Together, our study demonstrated that the G12D-9mer and G12D-10mer are structurally distinct, prototypical group 2 neoantigens, which are recognized by their cognate TCRs via discrete mechanisms.

\section{DO T CELL RESPONSES DIFFER BETWEEN MUTATED 'SELF' EPITOPES AND NOVEL 'NON-SELF' EPITOPES?}

Seminal studies indicated that clinical responses to check-point blockade were associated with mutational burden $(6,59)$. Further investigations have sought to identify classes of mutations that best associate with clinical success, with a focus on neoantigen quality not quantity $(44,60,61)$. Multiple studies suggest that neoantigens derived from anchor mutations (group 2) are more likely to be immunogenic and higher loads of anchor mutation neoantigens are associated with better prognosis than merely high numbers of neoantigens (62-64). One explanation for this is that group 2 neoantigens engender better $\mathrm{T}$ cell immunity than group 1 neoantigens, however molecular mechanisms for this effect are unclear. Group 2 neoantigens are more dissimilar to 'self peptides compared to group 1 and there is evidence that $\mathrm{T}$ cell responses to HIV are better to those peptides most dissimilar to 'self peptides (65). Similarly, neoantigens generated from novel open reading frames derived from insertion-deletion mutations (indels) are highly immunogenic and clearly dissimilar for WT 'self sequences (66). A potential mechanism is that group 2 neoantigen specific TCRs are of higher affinity, allowing stronger $\mathrm{T}$ cell responses. There are a limited number of biophysical studies describing the affinities of neoantigen specific 
TCRs making it difficult to draw broad conclusions. However, neoantigen specific TCRs have similar affinities to viral specific TCRs, all of which are much higher affinities than TCRs specific to those tumor antigens, which are 'self' peptides with dysregulated gene expressions in tumors (Figure 4B) (67). TCRs specific for group 2 neoantigens were higher affinity than those specific for group 1 (Table $\mathbf{1}$ and Figure 3B). One explanation for this trend is that high-affinity TCRs for group 1 neoantigens are likely deleted in the thymus owing to cross reactivity to 'self antigens. In contrast, WT peptides from group 2 neoantigens are likely not to be presented in the thymus and therefore high-affinity TCRs can survive negative selection, exemplified by TCR9a with an affinity of $16 \mathrm{nM}$ (15). It is important to stress however that data on neoantigens specific TCRs are limited and that the only group 2 neoantigen specific TCRs studied to date are HLA-C restricted, while the group 1 neoantigen specific TCRs are HLA-A restricted, which may impact their intrinsic affinities. Further studies of other neoantigen specific TCRs are needed to determine if this trend towards higher affinity in group 2 specific TCRs is maintained. It appears that intermediate affinity TCRs with low micromolar to high nanomolar affinities such as TCR10, 9b and 9c, are ideal for effective TCR therapy (68-70).

\section{INSIGHTS INTO SELECTING TCRS FOR IMMUNOTHERAPY}

Adoptive $\mathrm{T}$ cell transfer-based immunotherapy is a promising new approach to eliminate metastatic cancers. It assumes that many tumor infiltrating $\mathrm{T}$ cells (TIL) recognize tumor antigens specifically, but their circulating numbers are low in patients, thus natural TILs are insufficient to eradicate tumor cells. These TILs, however, can be expanded in vitro to large numbers and reinfused into cancer patients. The challenge is to know the right type of $\mathrm{T}$ cells to choose to expand into therapeutic reagents. Currently, the choice of $\mathrm{T}$ cells for expansion remains largely a trial-and-error empirical approach. Similar unknowns apply to 'off the shelf TCR based therapies that transduce T cells with tumor specific TCRs. In principle, there are three main criteria for the selection of anti-tumor T cells: affinity, antigenic breadth and persistence. In the case of treating a metastatic colorectal cancer with adoptive transfer of expanded TILs specific for KRAS (KRAS-G12D) neoantigen presented by HLA-C ${ }^{\star} 08: 02$, the transferred CD8+ T cells consists of four clonotypes, bearing TCR9a, 9b, 9c and TCR10, at abundance of 49.5\%, 6.9\%, 0.04\% and $19.1 \%$ of the total transferred $\mathrm{T}$ cells, respectively. The treatment resulted in regression of all metastases that retained HLA-C ${ }^{\star} 08: 02$ expression (51). Intuitively, high affinity receptors are more desirable in effective tumor killing, however high affinity TCRs appear to have diminished antigen sensitivity in vitro and in vivo (68-72). Another major concern of high affinity engineered TCRs is the potential for cross-reactivity, which can be lethal (73). However, this is unlikely to be a problem for naturally occurring high affinity TCRs specific for group 2 neoantigens such as TCR9a. Indeed, our data suggest that TCR9a and TCR10 have similar antigen sensitives with TCR9a being slightly more sensitive than TCR10 $(15,51,57)$. The problem with clinical use of TCR9a is that despite an abundant initial presence of the highest affinity receptor (50\% of the infusion), TCR9a was undetectable in the periphery on day 40 of post-transfer $(15,51)$. In contrast, the other three TCRs engrafted, resulting in a near inverse correlation between TCR affinity and their in vivo persistence $(15,51)$. In particular, TCR10 had the lowest affinity $(6 \mu \mathrm{M})$, made up $20 \%$ of the infusion and was maintained in the periphery at $10 \%$ of the repertoire 9 months post-transfer. The T cells with high affinity receptors disappeared faster in circulation during the adoptive transfer therapy (15), while lower affinity $\mathrm{T}$ cells persisted longer. Given the vast number of TCR9a ${ }^{+}$cells transferred $\left(\approx 7 \times 10^{10}\right)$ it seems highly unlikely that TCR9a ${ }^{+}$cells disappeared by decay, while the three other TCRs engrafted (51). A more likely scenario is that higher affinity $\mathrm{T}$ cells engage more effectively to cognate antigen (G12D-9mer) on the tumor resulting in higher tendency of activation induced cell death (AICD) rather than proliferation (68). It is not clear if all four TCR clonotypes were necessary for effective therapy in this case. In particular, was tumor recognition by the high affinity TCR, necessary for tumor regression? It is possible that the infusion of multiple TCRs specific for different antigens with a blend of characteristics including high affinity and long-term persistence was essential for effective tumor clearance. In this model, due to a 'cold' immune environment pre-infusion, a high affinity receptor like TCR9a is required to initiate tumor clearance. Subsequently, the other TCRs with lower affinities can engage the tumor and maintain tumor clearance, while not suffering activation induced cell death like the $\mathrm{T}$ cells bearing high affinity receptors. Namely, it may be necessary to select oligoclonal $\mathrm{T}$ cells with varying tumor affinities to balance the need for effective tumor killing and persistence in circulation. An alternative interpretation is that TCR9a was not necessary for clinical efficacy, and the therapeutic effect was due to TCRs with lower affinities, namely TCR10 and TCR9b\&c. Indeed, it appears that intermediate affinity TCRs with low micromolar to high nanomolar affinities such as TCR10, 9b and $9 \mathrm{c}$, are ideal for effective TCR therapy (68-70). Further experiments will need to investigate the validity of this model, specifically whether infusions of multiple TCRs with different antigen specificities, affinities and capacities for in vivo persistence are all necessary for effective adoptive $\mathrm{T}$ cell therapy. It is worth noting that the literature on high affinity TCRs is somewhat confused, in part due to the use of affinity by some investigators in place of avidity and a lack of consistency regarding what is meant by 'high affinity' (74). As an example, this 2012 study concluded that high affinity TCRs exhibited improved cytotoxicity, survival and reduced expression of inhibitory receptors (74). However, the affinity of the TCRs were not defined, and merely compared two TCRs with differing avidity measured by tetramer staining in a previous study (75). Both studies use affinity, when avidity is appropriate as direct affinity measurements were not made, and it is not clear where the affinities of the two TCRs lie on a scale from high micromolar to low nanomolar. For our part, we consider low affinity TCRs to 
have a $K_{D}>10 \mu \mathrm{M}$, intermediate, $K_{D}=100 \mathrm{nM}-10 \mu \mathrm{M}$, high, $\mathrm{K}_{\mathrm{D}}=1 \mathrm{nM}-100 \mathrm{nM}$, and supraphysiological, $\mathrm{K}_{\mathrm{D}}<1 \mathrm{nM}$.

In addition to antigenic affinity, the persistent expansion of TCR10 during adoptive transfer therapy highlights a potential need to include $\mathrm{T}$ cells with broader breadth in neoantigen recognition. In this case, TCR10 recognizes the KRAS-G12D 10mer peptide in a conformation not cross-reactive to the other three TCRs. It showed that the same oncogenic mutation may produce different conformational neoantigens that require non-cross-reactive $\mathrm{T}$ cell responses. Namely, the most potent $\mathrm{T}$ cell clones against one neoantigen may not be effective against other conformational variants of the same mutation-derived neoantigens and thus risking tumor escape. When taking both neoantigen variation and anti-tumor affinity into consideration, we propose a potentially more effective rational approach to screen TIL for adoptive T cell transfer therapy. Once the antigenic forms of a tumor antigen are defined, a combined structural and biochemical approach can be applied to select favorable therapeutic $\mathrm{T}$ cell clones with broad antigen affinities and specificities against variant neoantigens, both mutational and conformational.

\section{CONCLUSIONS}

Previous studies classified neoantigens into at least two classes, those with mutations at anchor residues (group 2) and those with mutations in existing 'self epitopes (group1) (32, 62-64). Recent structural studies have built on this work to provide unprecedented

\section{REFERENCES}

1. Kelly PN. The Cancer Immunotherapy Revolution. Science (2018) 359 (6382):1344-5. doi: 10.1126/science.359.6382.1344

2. Decker WK, da Silva RF, Sanabria MH, Angelo LS, Guimaraes F, Burt BM, et al. Cancer Immunotherapy: Historical Perspective of a Clinical Revolution and Emerging Preclinical Animal Models. Front Immunol (2017) 8:829. doi: 10.3389/fimmu.2017.00829

3. Pleasance ED, Cheetham RK, Stephens PJ, McBride DJ, Humphray SJ, Greenman CD, et al. A Comprehensive Catalogue of Somatic Mutations From a Human Cancer Genome. Nature (2010) 463(7278):191-6. doi: $10.1038 /$ nature08658

4. Stratton MR, Campbell PJ, Futreal PA. The Cancer Genome. Nature (2009) 458(7239):719-24. doi: 10.1038/nature07943

5. Bailey MH, Tokheim C, Porta-Pardo E, Sengupta S, Bertrand D, Weerasinghe A, et al. Comprehensive Characterization of Cancer Driver Genes and Mutations. Cell (2018) 174(4):1034-5. doi: 10.1016/j.cell.2018.07.034

6. Rizvi NA, Hellmann MD, Snyder A, Kvistborg P, Makarov V, Havel JJ, et al. Cancer Immunology. Mutational Landscape Determines Sensitivity to PD-1 Blockade in Non-Small Cell Lung Cancer. Science (2015) 348(6230):124-8. doi: $10.1126 /$ science.aaa1348

7. Snyder A, Makarov V, Merghoub T, Yuan J, Zaretsky JM, Desrichard A, et al. Genetic Basis for Clinical Response to CTLA-4 Blockade in Melanoma. N Engl J Med (2014) 371(23):2189-99. doi: 10.1056/NEJMoa1406498

8. Tran E, Robbins PF, Rosenberg SA. 'Final Common Pathway' of Human Cancer Immunotherapy: Targeting Random Somatic Mutations. Nat Immunol (2017) 18(3):255-62. doi: 10.1038/ni.3682

9. Leko V, Rosenberg SA. Identifying and Targeting Human Tumor Antigens for T Cell-Based Immunotherapy of Solid Tumors. Cancer Cell (2020) 38 (4):454-72. doi: 10.1016/j.ccell.2020.07.013 insight into how these structurally distinct classes of neoantigens are detected by $\mathrm{T}$ cells $(15,39-41)$. Recognition of neoantigens by $\mathrm{T}$ cells is an essential component of many successful immunotherapies (8). However, the biochemical and structural features of immunogenic neoantigens and effective therapeutic TCRs are still under investigation. While data are limited, there is evidence that TCRs specific for group 2 neoantigens can be of high affinity and this may explain in part why group 2 neoantigens are more immunogenic (62-64). The study of TCRs with demonstrated clinical efficacy revealed several traits associated with clinical success, such as a potential benefit of balancing between high affinity and high persistence. This multifaced requirement is best met with a rational approach in selecting TCRs with known biophysical characteristics for therapeutic use.

\section{AUTHOR CONTRIBUTIONS}

MS performed the experiments and wrote the manuscript. PS wrote the manuscript. All authors contributed to the article and approved the submitted version.

\section{FUNDING}

The funding of this work is provided by the Division of Intramural Research, National Institute of Allergy and Infectious Diseases, National Institutes of Health.
10. Parkhurst MR, Robbins PF, Tran E, Prickett TD, Gartner JJ, Jia L, et al. Unique Neoantigens Arise From Somatic Mutations in Patients With Gastrointestinal Cancers. Cancer Discov (2019) 9(8):1022-35. doi: 10.1158/2159-8290.CD-181494

11. Riley TP, Keller GLJ, Smith AR, Davancaze LM, Arbuiso AG, Devlin JR, et al. Structure Based Prediction of Neoantigen Immunogenicity. Front Immunol (2019) 10:2047. doi: 10.3389/fimmu.2019.02047

12. Garcia KC, Degano M, Stanfield RL, Brunmark A, Jackson MR, Peterson PA, et al. An Alphabeta T Cell Receptor Structure at 2.5 A and Its Orientation in the TCR-MHC Complex. Science (1996) 274(5285):209-19. doi: 10.1126/ science.274.5285.209

13. Garboczi DN, Ghosh P, Utz U, Fan QR, Biddison WE, Wiley DC. Structure of the Complex Between Human T-Cell Receptor, Viral Peptide and HLA-A2. Nature (1996) 384(6605):134-41. doi: 10.1038/384134a0

14. Bjorkman PJ, Saper MA, Samraoui B, Bennett WS, Strominger JL, Wiley DC. Structure of the Human Class I Histocompatibility Antigen, HLA-A2. Nature (1987) 329(6139):506-12. doi: 10.1038/329506a0

15. Sim MJW, Lu J, Spencer M, Hopkins F, Tran E, Rosenberg SA, et al. High-Affinity Oligoclonal TCRs Define Effective Adoptive T Cell Therapy Targeting Mutant KRAS-G12D. Proc Natl Acad Sci USA (2020) 117(23):12826-35. doi: 10.1073/ pnas. 1921964117

16. Neefjes J, Jongsma ML, Paul P, Bakke O. Towards a Systems Understanding of MHC Class I and MHC Class II Antigen Presentation. Nat Rev Immunol (2011) 11(12):823-36. doi: 10.1038/nri3084

17. Yewdell JW. DRiPs Solidify: Progress in Understanding Endogenous MHC Class I Antigen Processing. Trends Immunol (2011) 32(11):548-58. doi: 10.1016/j.it.2011.08.001

18. Yewdell JW, Reits E, Neefjes J. Making Sense of Mass Destruction: Quantitating MHC Class I Antigen Presentation. Nat Rev Immunol (2003) 3(12):952-61. doi: 10.1038/nri1250 
19. Wearsch PA, Cresswell P. The Quality Control of MHC Class I Peptide Loading. Curr Opin Cell Biol (2008) 20(6):624-31. doi: 10.1016/ j.ceb.2008.09.005

20. Stephen AG, Esposito D, Bagni RK, McCormick F. Dragging Ras Back in the Ring. Cancer Cell (2014) 25(3):272-81. doi: 10.1016/j.ccr.2014.02.017

21. Seliger B, Kloor M, Ferrone S. HLA Class II Antigen-Processing Pathway in Tumors: Molecular Defects and Clinical Relevance. Oncoimmunology (2017) 6 (2):e1171447. doi: 10.1080/2162402X.2016.1171447

22. Tran E, Turcotte S, Gros A, Robbins PF, Lu YC, Dudley ME, et al. Cancer Immunotherapy Based on Mutation-Specific CD4+ T Cells in a Patient With Epithelial Cancer. Science (2014) 344(6184):641-5. doi: 10.1126/science.1251102

23. Pos W, Sethi DK, Wucherpfennig KW. Mechanisms of Peptide Repertoire Selection by HLA-Dm. Trends Immunol (2013) 34(10):495-501. doi: 10.1016/ j.it.2013.06.002

24. Robinson J, Guethlein LA, Cereb N, Yang SY, Norman PJ, Marsh SGE, et al. Distinguishing Functional Polymorphism From Random Variation in the Sequences of >10,000 HLA-A, -B and -C Alleles. PloS Genet (2017) 13(6): e1006862. doi: 10.1371/journal.pgen.1006862

25. Robinson J, Barker DJ, Georgiou X, Cooper MA, Flicek P, Marsh SGE. IPDIMGT/HLA Database. Nucleic Acids Res (2020) 48(D1):D948-D55. doi: 10.1093/nar/gkz950

26. Madden DR. The Three-Dimensional Structure of Peptide-MHC Complexes. Annu Rev Immunol (1995) 13:587-622. doi: 10.1146/annurev.iy.13.040195. 003103

27. Istrail S, Florea L, Halldorsson BV, Kohlbacher O, Schwartz RS, Yap VB, et al. Comparative Immunopeptidomics of Humans and Their Pathogens. Proc Natl Acad Sci USA (2004) 101(36):13268-72. doi: 10.1073/pnas.0404740101

28. Sarkizova S, Klaeger S, Le PM, Li LW, Oliveira G, Keshishian H, et al. A Large Peptidome Dataset Improves HLA Class I Epitope Prediction Across Most of the Human Population. Nat Biotechnol (2020) 38(2):199-209. doi: 10.1038/ s41587-019-0322-9

29. Di Marco M, Schuster H, Backert L, Ghosh M, Rammensee HG, Stevanovic S. Unveiling the Peptide Motifs of HLA-C and HLA-G From Naturally Presented Peptides and Generation of Binding Prediction Matrices. J Immunol (2017) 199(8):2639-51. doi: 10.4049/jimmunol.1700938

30. Falk K, Rotzschke O, Stevanovic S, Jung G, Rammensee HG. Allele-Specific Motifs Revealed by Sequencing of Self-Peptides Eluted From MHC Molecules. Nature (1991) 351(6324):290-6. doi: 10.1038/351290a0

31. Hunt DF, Henderson RA, Shabanowitz J, Sakaguchi K, Michel H, Sevilir N, et al. Characterization of Peptides Bound to the Class I MHC Molecule HLAA2.1 by Mass Spectrometry. Science (1992) 255(5049):1261-3. doi: 10.1126/ science. 1546328

32. Fritsch EF, Rajasagi M, Ott PA, Brusic V, Hacohen N, Wu CJ. HLA-Binding Properties of Tumor Neoepitopes in Humans. Cancer Immunol Res (2014) 2 (6):522-9. doi: 10.1158/2326-6066.CIR-13-0227

33. Rossjohn J, Gras S, Miles JJ, Turner SJ, Godfrey DI, McCluskey J. T Cell Antigen Receptor Recognition of Antigen-Presenting Molecules. Annu Rev Immunol (2015) 33:169-200. doi: 10.1146/annurev-immunol-032414-112334

34. Rudolph MG, Stanfield RL, Wilson IA. How TCRs Bind MHCs, Peptides, and Coreceptors. Annu Rev Immunol (2006) 24:419-66. doi: 10.1146/ annurev.immunol.23.021704.115658

35. Huseby ES, Crawford F, White J, Marrack P, Kappler JW. InterfaceDisrupting Amino Acids Establish Specificity Between T Cell Receptors and Complexes of Major Histocompatibility Complex and Peptide. Nat Immunol (2006) 7(11):1191-9. doi: 10.1038/ni1401

36. Schatz DG, Ji Y. Recombination Centres and the Orchestration of V(D)J Recombination. Nat Rev Immunol (2011) 11(4):251-63. doi: 10.1038/nri2941

37. Spits H. Development of Alphabeta T Cells in the Human Thymus. Nat Rev Immunol (2002) 2(10):760-72. doi: 10.1038/nri913

38. Germain RN. T-Cell Development and the CD4-CD8 Lineage Decision. Nat Rev Immunol (2002) 2(5):309-22. doi: 10.1038/nri798

39. Wu D, Gallagher DT, Gowthaman R, Pierce BG, Mariuzza RA. Structural Basis for Oligoclonal T Cell Recognition of a Shared P53 Cancer Neoantigen. Nat Commun (2020) 11(1):2908. doi: 10.1038/s41467-020-16755-y

40. Devlin JR, Alonso JA, Ayres CM, Keller GLJ, Bobisse S, Vander Kooi CW, et al. Structural Dissimilarity From Self Drives Neoepitope Escape From Immune Tolerance. Nat Chem Biol (2020) 16(11):1269-76. doi: 10.1038/ s41589-020-0610-1
41. Deng L, Langley RJ, Brown PH, Xu G, Teng L, Wang Q, et al. Structural Basis for the Recognition of Mutant Self by a Tumor-Specific, MHC Class II-Restricted T Cell Receptor. Nat Immunol (2007) 8(4):398-408. doi: 10.1038/ni1447

42. Jurtz V, Paul S, Andreatta M, Marcatili P, Peters B, Nielsen M. NetMHCpan4.0: Improved Peptide-MHC Class I Interaction Predictions Integrating Eluted Ligand and Peptide Binding Affinity Data. J Immunol (2017) 199 (9):3360-8. doi: 10.4049/jimmunol.1700893

43. Hellman LM, Yin L, Wang Y, Blevins SJ, Riley TP, Belden OS, et al. Differential Scanning Fluorimetry Based Assessments of the Thermal and Kinetic Stability of Peptide-MHC Complexes. J Immunol Methods (2016) 432:95-101. doi: 10.1016/j.jim.2016.02.016

44. McGranahan N, Furness AJ, Rosenthal R, Ramskov S, Lyngaa R, Saini SK, et al. Clonal Neoantigens Elicit T Cell Immunoreactivity and Sensitivity to Immune Checkpoint Blockade. Science (2016) 351(6280):1463-9. doi: 10.1126/science.aaf1490

45. Sabapathy K, Lane DP. Therapeutic Targeting of P53: All Mutants Are Equal, But Some Mutants Are More Equal Than Others. Nat Rev Clin Oncol (2018) 15(1):13-30. doi: 10.1038/nrclinonc.2017.151

46. Deniger DC, Pasetto A, Robbins PF, Gartner JJ, Prickett TD, Paria BC, et al. TCell Responses to TP53 "Hotspot" Mutations and Unique Neoantigens Expressed by Human Ovarian Cancers. Clin Cancer Res (2018) 24 (22):5562-73. doi: 10.1158/1078-0432.CCR-18-0573

47. Lo W, Parkhurst M, Robbins PF, Tran E, Lu YC, Jia L, et al. Immunologic Recognition of a Shared P53 Mutated Neoantigen in a Patient With Metastatic Colorectal Cancer. Cancer Immunol Res (2019) 7(4):534-43. doi: 10.1158/ 2326-6066.CIR-18-0686

48. Echchannaoui H, Petschenka J, Ferreira EA, Hauptrock B, Lotz-Jenne C, Voss RH, et al. A Potent Tumor-Reactive P53-Specific Single-Chain TCR Without On- or Off-Target Autoimmunity In Vivo. Mol Ther (2019) 27(1):261-71. doi: 10.1016/j.ymthe.2018.11.006

49. Malekzadeh P, Yossef R, Cafri G, Paria BC, Lowery FJ, Jafferji M, et al. Antigen Experienced T Cells From Peripheral Blood Recognize P53 Neoantigens. Clin Cancer Res (2020) 26(6):1267-76. doi: 10.1158/1078-0432.CCR-19-1874

50. Pearlman AH, Hwang MS, Konig MF, Hsiue EH-C, Douglass J, DiNapoli SR, et al. Targeting Public Neoantigens for Cancer Immunotherapy. Nat Cancer (2021) 2(5):487-97. doi: 10.1038/s43018-021-00210-y

51. Tran E, Robbins PF, Lu YC, Prickett TD, Gartner JJ, Jia L, et al. T-Cell Transfer Therapy Targeting Mutant KRAS in Cancer. N Engl J Med (2016) 375(23):2255-62. doi: 10.1056/NEJMoa1609279

52. June $\mathrm{CH}$. Drugging the Undruggable Ras - Immunotherapy to the Rescue? $N$ Engl J Med (2016) 375(23):2286-9. doi: 10.1056/NEJMe1612215

53. Hobbs GA, Der CJ, Rossman KL. RAS Isoforms and Mutations in Cancer at a Glance. J Cell Sci (2016) 129(7):1287-92. doi: 10.1242/jcs.182873

54. Cox AD, Fesik SW, Kimmelman AC, Luo J, Der CJ. Drugging the Undruggable RAS: Mission Possible? Nat Rev Drug Discovery (2014) 13 (11):828-51. doi: 10.1038/nrd4389

55. Tran E, Ahmadzadeh M, Lu YC, Gros A, Turcotte S, Robbins PF, et al. Immunogenicity of Somatic Mutations in Human Gastrointestinal Cancers. Science (2015) 350(6266):1387-90. doi: 10.1126/science.aad1253

56. Parker KC, Shields M, DiBrino M, Brooks A, Coligan JE. Peptide Binding to MHC Class I Molecules: Implications for Antigenic Peptide Prediction. Immunol Res (1995) 14(1):34-57. doi: 10.1007/BF02918496

57. Sim MJW, Stotz Z, Lu J, Brennan P, Long EO, Sun PD. T Cells Discriminate Between Groups C1 and C2 HLA-C. bioRxiv (2021):2021.11.11.468262.

58. Venturi V, Price DA, Douek DC, Davenport MP. The Molecular Basis for Public T-Cell Responses? Nat Rev Immunol (2008) 8(3):231-8. doi: 10.1038/nri2260

59. Le DT, Uram JN, Wang H, Bartlett BR, Kemberling H, Eyring AD, et al. PD-1 Blockade in Tumors With Mismatch-Repair Deficiency. N Engl J Med (2015) 372(26):2509-20. doi: 10.1056/NEJMoa1500596

60. McGranahan N, Swanton C. Neoantigen Quality, Not Quantity. Sci Transl Med (2019) 11(506):1-3. doi: 10.1126/scitranslmed.aax7918

61. Luksza M, Riaz N, Makarov V, Balachandran VP, Hellmann MD, Solovyov A, et al. A Neoantigen Fitness Model Predicts Tumour Response to Checkpoint Blockade Immunotherapy. Nature (2017) 551(7681):517-20. doi: 10.1038/nature24473

62. Duan F, Duitama J, Al Seesi S, Ayres CM, Corcelli SA, Pawashe AP, et al. Genomic and Bioinformatic Profiling of Mutational Neoepitopes Reveals New Rules to Predict Anticancer Immunogenicity. J Exp Med (2014) 211(11):223148. doi: $10.1084 /$ jem. 20141308 
63. Rech AJ, Balli D, Mantero A, Ishwaran H, Nathanson KL, Stanger BZ, et al. Tumor Immunity and Survival as a Function of Alternative Neopeptides in Human Cancer. Cancer Immunol Res (2018) 6(3):276-87. doi: 10.1158/2326-6066.CIR-17-0559

64. Ghorani E, Rosenthal R, McGranahan N, Reading JL, Lynch M, Peggs KS, et al. Differential Binding Affinity of Mutated Peptides for MHC Class I Is a Predictor of Survival in Advanced Lung Cancer and Melanoma. Ann Oncol (2018) 29(1):271-9. doi: 10.1093/annonc/mdx687

65. Rolland M, Nickle DC, Deng W, Frahm N, Brander C, Learn GH, et al. Recognition of HIV-1 Peptides by Host CTL Is Related to HIV-1 Similarity to Human Proteins. PloS One (2007) 2(9):e823. doi: 10.1371/journal. pone.0000823

66. Turajlic S, Litchfield K, Xu H, Rosenthal R, McGranahan N, Reading JL, et al. Insertion-And-Deletion-Derived Tumour-Specific Neoantigens and the Immunogenic Phenotype: A Pan-Cancer Analysis. Lancet Oncol (2017) 18 (8):1009-21. doi: 10.1016/S1470-2045(17)30516-8

67. Aleksic M, Liddy N, Molloy PE, Pumphrey N, Vuidepot A, Chang KM, et al. Different Affinity Windows for Virus and Cancer-Specific T-Cell Receptors: Implications for Therapeutic Strategies. Eur J Immunol (2012) 42(12):3174-9. doi: 10.1002/eji.201242606

68. Presotto D, Erdes E, Duong MN, Allard M, Regamey PO, Quadroni M, et al. Fine-Tuning of Optimal TCR Signaling in Tumor-Redirected CD8 T Cells by Distinct TCR Affinity-Mediated Mechanisms. Front Immunol (2017) 8:1564. doi: 10.3389/fimmu.2017.01564

69. Lever M, Lim HS, Kruger P, Nguyen J, Trendel N, Abu-Shah E, et al. Architecture of a Minimal Signaling Pathway Explains the T-Cell Response to a 1 Million-Fold Variation in Antigen Affinity and Dose. Proc Natl Acad Sci USA (2016) 113(43):E6630-E8. doi: 10.1073/pnas.1608820113

70. Thomas S, Xue SA, Bangham CR, Jakobsen BK, Morris EC, Stauss HJ. Human T Cells Expressing Affinity-Matured TCR Display Accelerated Responses But Fail to Recognize Low Density of MHC-Peptide Antigen. Blood (2011) 118 (2):319-29. doi: 10.1182/blood-2010-12-326736

71. Corse E, Gottschalk RA, Krogsgaard M, Allison JP. Attenuated T Cell Responses to a High-Potency Ligand In Vivo. PloS Biol (2010) 8(9):1-12. doi: 10.1371/journal.pbio.1000481

72. Irving M, Zoete V, Hebeisen M, Schmid D, Baumgartner P, Guillaume P, et al. Interplay Between T Cell Receptor Binding Kinetics and the Level of Cognate
Peptide Presented by Major Histocompatibility Complexes Governs CD8+ T Cell Responsiveness. J Biol Chem (2012) 287(27):23068-78. doi: 10.1074/ jbc.M112.357673

73. Linette GP, Stadtmauer EA, Maus MV, Rapoport AP, Levine BL, Emery L, et al. Cardiovascular Toxicity and Titin Cross-Reactivity of Affinity-Enhanced $\mathrm{T}$ Cells in Myeloma and Melanoma. Blood (2013) 122(6):863-71. doi 10.1182/blood-2013-03-490565

74. Bos R, Marquardt KL, Cheung J, Sherman LA. Functional Differences Between Low- and High-Affinity CD8(+) T Cells in the Tumor Environment. Oncoimmunology (2012) 1(8):1239-47. doi: 10.4161/onci.21285

75. Lyman MA, Nugent CT, Marquardt KL, Biggs JA, Pamer EG, Sherman LA. The Fate of Low Affinity Tumor-Specific CD8+ T Cells in TumorBearing Mice. J Immunol (2005) 174(5):2563-72. doi: 10.4049/jimmunol. 174.5.2563

Author Disclaimer: The content of this publication does not necessarily reflect the views or policies of the Department of Health and Human Services, nor does mention of trade names, commercial products, or organizations imply endorsement by the U.S. Government.

Conflict of Interest: The authors declare that the research was conducted in the absence of any commercial or financial relationships that could be construed as a potential conflict of interest.

Publisher's Note: All claims expressed in this article are solely those of the authors and do not necessarily represent those of their affiliated organizations, or those of the publisher, the editors and the reviewers. Any product that may be evaluated in this article, or claim that may be made by its manufacturer, is not guaranteed or endorsed by the publisher.

Copyright (c) 2022 Sim and Sun. This is an open-access article distributed under the terms of the Creative Commons Attribution License (CC BY). The use, distribution or reproduction in other forums is permitted, provided the original author(s) and the copyright owner(s) are credited and that the original publication in this journal is cited, in accordance with accepted academic practice. No use, distribution or reproduction is permitted which does not comply with these terms. 